\title{
Filosofia da informação: reflexos e reflexões
}

\section{Philosqphy of information: indications and reflections}

Marivalde Moacir FRANCELIN ${ }^{1}$

Caio PELLEGATTI ${ }^{2}$

R E S U M O

A B S T R A C T

A Filosofia não pode restringir-se apenas à busca da verdade. A informação não é apenas suporte para o conhecimento. $O$ pensamento no século $X X I$, encontra-se perante dilemas até então desconhecidos ou evitados. A sujeição e a prova de "novos" pensamentos ocorrem através de crises e rupturas. 0 processo de conhecer o conhecimento ou o de pensar o pensamento, indubitavelmente foram, e são importantes etapas no desenvolvimento do total conhecimento humano. Buscando-se a inserção e o entendimento da própria informação relacionada a esses processos, o presente trabalho propõe uma filosofia que pense essa informação, ou seja, uma Filosofia da Informação.

Palavras-chave: informação, filosofia, filosofia da informação, ciência da informação, conhecimento, complexidade.

Philosophy cannot restrict itself solely to the search for truth. Information Science is not only a support. In the $21^{\text {st }}$. Century, thought finds itself before dilemmas which had been ignored or unknown up to now. Subjection and testing of "new" thoughts, occur through crises and ruptures. The processes of "getting to know"

\footnotetext{
${ }^{1}$ Mestre em Biblioteconomia e Ciência da Informação, PUC-Campinas. Docente, Departamento de Direito e Departamento Economia e Administração, Anhanguera Ensino Superior, Faculdades de Valinhos. Av. Invernada, 595, Vera Cruz, 13271-450, Valinhos, SP, Brasil. Correspondência para/Correspondence to: M.M. FRANCEITM. E-mail: mfrancelin@yahoo.com.br 2 Matemático, Analista de Sistemas Senior - BIBNET (Bibliotecas Digitais). Mestrando, Curso de Biblioteconomia e Ciência da Informação, PUC-Campinas. E-mail: caio@aleph-exlibris.com.br Recebido em 29/9/2004 e aceito para publicação em 10/9/2004.
} 
the knowledge or "of thinking" the thought, undoubtedly have been, and are, important stages in the development of what we understand as being the total human knowledge. Seeking to understand and to insert the very information related to those processes, the present article proposes a philosophy that will reflect upon such information, namely, a Philosophy of Information.

Key words: information, philosophy, philosophy of information, information science, knowledge, complexity.

\section{N T R O D U Ç Ã O}

\section{A informação sob o objeto informação}

Abordando-se uma questão sobre informação e conhecimento, pode-se relembrar que informare significa dar forma a alguma coisa, formar algo, alguma idéia. Incluiu-se em sua definição o termo "dado" como necessário à constituição de uma informação, assim como o termo "comunicação". Isso resume as relações entre informação e conhecimento e seus componentes em um ambiente histórico-comunicacional (LE COADIC, 1996; McGARRY, 1999; PAIVA, 2002; ROBREDO, 2003). Recentemente, incorporou-se, como necessário ao próprio significado da palavra informação, o termo conhecimento, trazendo maior nível de complexidade em torno do próprio conceito de informação (ARAÚJO, 2002; SILVA, 2003). Percepção, representação, cognição, sentidos e sentimentos, sensações e intuição agora podem fazer parte dessa estrutura.

A esfera da informação é uma realidade relativa que compreende o conjunto dos acontecimentos que ocorrem no mundo e formam o nosso meio ambiente. Os acontecimentos são tanto mais informativos quanto menos previsíveis e portanto mais inesperados (RODRIGUES, 1999, p.20).

Os conceitos se modificam de disciplina para disciplina (Filosofia, Lingüística, Computação, Educação, Sociologia, Biologia, Física,
Química, Matemática, Arqueologia). Saracevic (1974, p.60) já dizia que "Numa disposição formal, o fenômeno da informação é estudado em muitas disciplinas diversas, confirmando assim as ramificações complexas e muitas manifestações a ele associadas". Em tais situações, as relações de informação vão do suporte físico (papel) ao suporte biológico (célula).

A informação apresenta-se-nos em estruturas, formas, modelos, figuras; em idéias e ídolos; em índices, imagens e ícones; no comércio e na mercadoria; em continuidade e descontinuidade; em sinais, signos, significantes e símbolos; em gestos, posições e conteúdos; em freqüências, entonações, ritmos e inflexões; em presenças e ausências; em palavras, em acções e em silêncios; em visões e silogismos. É a organização da própria variedade (WILDEN, 2000, p.11).

Pode-se, nesse sentido, configurar distintos contextos e fenômenos de informação que dão um certo tipo de suporte a eventos conhecidos como sociedades de informação (WERTHEIN, 2000; BRENNAND, 2002), sociedades, políticas e governos em rede (HARRIS, 2002). Produção de conhecimento "artificial" (SAN SEGUNDO MANUEL, 2003) e auto-geração de informação (SILVA, 1996) são campos de estudo que podem ser citados como exemplos diante de perspectivas recentes.

A informação está por isso intimamente associada à natureza relativamente 
inexplicada e inexplicável dos fenômenos, ao facto de a razão humana não os conseguir dominar e de ocorrerem no mundo à nossa volta sem aviso prévio, fora do controlo e do domínio da liberdade humana, de intervirem de maneira brutal e inesperada. As regras que regem a informação assemelham-se portanto às leis da natureza: não dependem do controlo da razão humana nem fazem intervir a nossa liberdade de escolha. O mecanismo que rege os fenômenos que pertencem à esfera informativa é, por isso, o do automatismo que encontramos igualmente nos reflexos condicionados (RODRIGUES, 1999, p.21).

Ambienta-se, por sua vez, no que agora se pretende chamar de contextos e realidades de informação, a informação como subsídio ao desenvolvimento científico e tecnológico (SANTOS, 2003). Por outro lado, a informação, vista como mercadoria, dá origem ao denominado "mercado" de informação, manifestando desigualdades na própria conjuntura global de produção de informação.

Informação e conhecimento estabelecem-se na pós-modernidade por uma aparente via de ruptura com o "mito" da razão moderna (BRAGA, 1974; JAPIASSU, 1977). Surgem as chamadas revoluções científicas e os "novos" paradigmas para a ciência (KUHN, 2001). A abertura para as relações disciplinares (interdisciplinaridade) fornecem subsídios para o desenvolvimento de teorias e metodologias sobre o objeto informação (PINHEIRO, 1999). O aprendizado sobre o conhecimento transformase em possibilidades de desenvolvimento, tanto filosófico como científico, ao pesquisador/ profissional da informação.

Nesse sentido, os conceitos sobre informação parecem estar distantes de um certo tipo de diminuição de complexidade. Pode-se dizer que alguns estudos encontram-se em fase inicial, porém, já indicam possibilidades em torno das pesquisas em informação que vão além de, por exemplo, análise de suportes. Assim, Floridi (2002a; 2002b; 2004) indica um caminho diferente e interessante ao propor uma Filosofia da Informação ${ }^{3}$ (Philosophy of Information).

O que é Filosofia da Informação? (What is the Philosophy of Information?) pergunta Floridi (2002b) em um de seus textos sobre o tema. $\mathrm{Na}$ realidade, sua proposta de pensar filosoficamente ${ }^{4}$ a informação parte de uma lógica informática e computacional onde teorias semântica, matemática e comunicacional apresentam-se como fundamentos para sua análise.

Partindo-se de uma abordagem do texto de Floridi (2002b) mencionado acima, tentar-se-á analisar algumas questões sobre a informação através do campo da Ciência da Informação com o objetivo de propor a construção de estruturas conceituais, teóricas e epistemológicas múltiplas.

Isso talvez se justifique a partir da conscientização de que as disciplinas científicas, ao longo de seus desenvolvimentos, parecem buscar aproximações conceituais além de suas fronteiras epistemológicas. Essa característica parece ser apontada como transgressora ${ }^{5}$. Nesse

\footnotetext{
${ }^{3}$ Lembrar porém, que Ilharco (2003) publicou, emportuguês, o livro Fil losofia da Informação e Mostafa (1985) já havia dito que a "[... Ciência da Informação não pode prescindir de uma fi losofia da informação, todavia a fi losofia da informação não pode ficar acima da ciência da informação porque aí estaríamos na dicotomia kantiana entre razão teorética e razão prática" (MOSTAFA, 1985, p.117).

${ }^{4}$ O que se está tentando abordar, neste momento, não é a Filosofia, mas, a Filosofia da. Este ponto é importante, pois, segundo Ferrater Mbra (1982) , " [... cada sistema filosófico pode valer uma resposta à pergunta acerca do que é a fillosofia e também acerca do que representa a actividade filosófica para a vida humana" (FERRATER MORA, 1982, p.160) . Isto conduz a supor-se que a Filosofia da Informação pode compor-se como uma dessas respostas.

${ }^{5}$ Ressalta-se que o sentido ut i lizado para o termo transgressão tenta caracterizar algo que está além do tradicionalmente aceito, que transforma não pela violência nem pela força, mas pela abertura ao diálogo entre campos distintos do conhecimento.
} 
sentido, configura-se como uma proposta, ou seja, o pensamento transgressor parte de um conjunto pré-elaborado de conceitos. Uma estrutura conceitual disciplinar teria que acompanhar mudanças no espaço e no tempo científicos, significando a adoção de princípios epistemológicos e metodológicos fundamentados em paradigmas complexos.

\section{A Filosofia da Informação}

Luciano Floridi é professor de Lógica e Epistemologia na Universidade de Bari (Itália) e faz parte do departamento de Ciência da Computação em Oxford (Inglaterra), onde também coordena um grupo de pesquisa sobre ética e informação. Tem partido da Filosofia para as suas indagações em torno e no interior da Sociedade da Informação modelada, em finais do ano de 1990, pelo impacto (ainda em processo) das Tecnologias da Informação e Comunicação (TICs).

Segundo Floridi (2002b), pesquisas de computação e informação teorética (theoretic) em filosofia tornaram-se campo fértil e penetrante, as quais revitalizam questões filosóficas antigas, propõem novos problemas, e contribuem para re-conceituar algumas visões sobre o mundo, produzindo resultados interessantes e importantes.

Neste caso, vários "rótulos" foram sugeridos e utilizados para este novo campo, tais como: filosofia cibernética (cyberphilosophy), filosofia digital, filosofia computacional, filosofia de Inteligência Artificial (IA), filosofia do artificial e epistemologia artificial (FLORIDI, 2002b, p.2). Analisando-se o processo histórico e conceitual que levou ao aparecimento da Filosofia da Informação, Floridi diz que a filosofia de Inteligência Artificial era um paradigma prematuro que, não obstante, abriu caminho para o aparecimento da Filosofia da Informação.

A Filosofia da Informação evolui como um estágio mais recente da dialética entre inovação conceitual e a escolástica (doutrina da Idade Média que tratava do problema da relação fé e razão). É definida como um campo filosófico preocupado com a investigação crítica, de natureza conceitual e princípios básicos da informação, incluindo sua dinâmica, utilização e ciências, e a elaboração e aplicação da informação teorética (theoretic) e metodologias computacionais para a resolução de problemas filosóficos. Como um novo campo de estudos destinase, explicitamente, à interpretação clara e precisa da pergunta "Qual é a natureza da informação?" (What is the nature of information?), tentando demonstrar sua "legitimidade" (FLORIDI, 2002b, p.14). Segundo o autor, a Filosofia da Informação pressupõe que um problema ou uma explicação pode ser legitimamente e genuinamente reduzido para um problema informacional.

Os filósofos começaram a endereçar novos desafios intelectuais advindos do "mundo" da informação e da sociedade da informação (LEVY, 1999; 2000). Na perspectiva de Floridi, a Filosofia da Informação tenta expandir a fronteira da pesquisa filosófica, não colocando juntos tópicos pré-existentes e, deste modo, reordenando o cenário filosófico, incluindo novas áreas de investigação filosófica. Nesse caso, a Filosofia da Informação tem lutado para ser reconhecida, porém, ainda não encontrou lugar no programa filosófico tradicional. A partir disso, Floridi pergunta: já é hora de estabelecer a Filosofia da Informação como um campo de estudos maduro? A resposta pode ser afirmativa, pois, entendese que cultura e sociedade e os processos de desenvolvimento filosófico contribuíram e continuam a contribuir para isso. Entretanto, pergunta novamente Floridi: que tipo de Filosofia da Informação se espera desenvolver? A resposta para esta questão parece pressupor uma visão clara da posição da Filosofia da Informação na história do pensamento, uma visão provavelmente obtida, paradoxalmente, somente a posteriori.

Portanto, segundo Floridi (2002b), a Filosofia da Informação possui, mesmo para a 
Filosofia, um extraordinário vocabulário conceitual. Isso porque pode-se contar com conceitos informacionais sempre que um entendimento completo de uma série de eventos está indisponível ou torna-se desnecessário para prover uma certa explicação. Em Filosofia isso significa que, virtualmente, qualquer assunto pode ser reformulado em termos informacionais. Essa capacidade semântica é uma das vantagens, segundo Floridi, da Filosofia da Informação entendida como uma metodologia, mostrando que se está diante de um certo tipo de paradigma abrangente, inteligível e descritível em termos de uma filosofia informacional.

\section{Tansgredindo: caminhos/descaminhos para uma Filosofia da Informação}

Parte-se da idéia de que a Filosofia é uma expressão organizada, em um campo de estudo, dos primeiros questionamentos do ser humano no Ocidente sobre a origem das coisas e, depois, sobre a origem do conhecimento. Mais de vinte e cinco séculos se passaram desde Tales e o ser humano ainda continua a interrogar-se. A produção e a reprodução do conhecimento, a força da ciência e a criação das comunidades científicas, o desenvolvimento dos experimentos científicos e a chegada das tecnologias de infor-mação, marcam, de alguma maneira, a história do conhecimento humano. Essa história inicia-se pela oralidade, passa ao manuscrito, depois à impressão e chega à virtualidade.

Todo campo, o campo científico por exemplo, é um campo de forças e um campo de lutas para conservar ou transformar esse campo de forças. Pode-se, num primeiro momento, descrever um espaço científico ou um espaço religioso como um mundo físico, comportando as relações de força, as relações de dominação. Os agentes - por exemplo, as empresas no caso do campo econômico - criam o espaço, e o espaço só existe (de alguma maneira) pelos agentes que aí se encontram. Uma grande empresa deforma todo o espaço econômico conferindo-lhe uma certa estrutura. No campo científico, Einstein, tal como uma grande empresa, deformou todo o espaço em torno de si. Essa metáfora 'einsteiniana' a propósito do próprio Einstein significa que não há físico, pequeno ou grande, em Brioude ou em Harvard que (independentemente de qualquer contato direto, de qualquer interação) não tenha sido tocado, perturbado, marginalizado pela intervenção de Einstein, tanto quanto um grande estabelecimento que, ao baixar seus preços, lança fora do espaço econômico toda uma população de pequenos empresários (BOURDIEU, 2004, p.22-23).

Na pós-modernidade as instituições se multiplicam em veículos de comunicação e transmissão de informações. O desenvolvimento tecnológico continua a transformar o mundo. Os pensadores já se antecipam em pensar essa tecnologia e seus impactos, agora é necessário não apenas pensar a informação que está sendo veiculada e transmitida, mas também a informação que está sendo apropriada e as influências internas e externas ao ser cognoscente.

Assim, a Filosofia da Informação busca analisar os mais variados assuntos que estejam relacionados à informação. A Filosofia da Informação se preocupa menos em discutir as ferramentas e as operações que dão suporte à informação do que as relações entre o ser humano e a informação. O ambiente de estudo da Filosofia da Informação é o próprio ambiente do ser humano. Nesse ambiente encontra-se a informação. A realidade humana é que possibilita a constituição da informação e sua veiculação. É nessa realidade que serão analisadas e pensadas as formas de trânsito da informação.

O método de estudo da Filosofia da Informação é relacional, ou seja, baseia-se na complexidade do pensamento e do cotidiano humanos. O objeto de estudo da Filosofia da 
Informação é a informação "liberta". O que poderia ser uma informação liberta? É aquela que não está presa a um domínio, que não é dominada. E o que é uma informação dominada? Seria aquilo que se sabe que é uma informação em condições de ser manipulada. A informação "liberta" seria o oposto, estaria fora do controle humano, mas não de sua percepção. Analogamente, Bourdieu (2004, p.21) diz que:

Em outras palavras, é preciso escapar à alternativa da 'ciência pura', totalmente livre de qualquer necessidade social, e da 'ciência escrava', sujeita a todas as demandas políticos-econômicas. O campo científico é um mundo social e, como tal, faz imposições, solicitações etc., que são, no entanto, relativamente independentes das pressões do mundo social global que o envolve.

É nesse ambiente que a Filosofia da Informação irá estudar e pensar a informação ${ }^{6}$. Um universo de representação, além do paradigma, no qual se justifica os conceitos de informação, pois, como já o disse Foskett (1980, p.20), "Um paradigma se baseia, de fato, em informação [...]".

De certa maneira, porém, o conceito de paradigma parece se fechar em si mesmo no momento em que diz o que é um paradigma. Essa estrutura fechada não ajuda muito ao se discutir qual o paradigma necessário ao desenvolvimento do conhecimento. A informação encontra-se no centro de uma discussão ou há uma discussão em seu centro em torno de uma suposta necessidade paradigmática. A desmistificação desse paradigma seria a porta de entrada para o desenvolvimento do pensamento em Filosofia da Informação.

Parecem ser longas as revisões sobre a teoria kuhniana nesse sentido (por exemplo, em Ciência da Informação, Nehmy (1996) e Eugênio,
França e Perez (1996). Mais longa ainda é a verbalização sobre a necessidade de identificação e definição de "paradigmas". Isso não significa que seja um modismo. Talvez, haja realmente a necessidade de um encontro paradigmático em informação. Mas, como fazer para localizar essa referência? Sabe-se que a informação é um rico objeto de estudo, não podendo, por outro lado, ser reduzida a um único paradigma.

A informação é em si ambivalente, tanto em quem a pronuncia quanto em quem a recebe. Em todos os momentos passa pelo filtro da subjetividade, além de sua dimensão estar limitada pelo aparato perceptor e conceitualizador. Mas é esta ambivalência que resgata sempre a possibilidade de criar, inventar. Se tudo fosse apenas lógico, seria apenas repetitivo. O mundo da informação é agitado, conturbado, porque é, ao mesmo tempo, intrinsecamente manipulado e impossível de ser totalmente manipulado (DEMO, 2000, p.41).

Assim, ao invés de um único paradigma, encontrar-se-iam vários paradigmas relacionados como eventos constitutivos da própria informação. Essa informação não poderia passar por nenhum tipo de processo determinista, visto que seria o seu inverso que proporcionaria o desenvolvimento dessa estrutura paradigmática plurifacetada.

A previsão de irracionalismos reinantes levando ao aniquilamento do homem biológico dotado de sentimentos e o transformando em uma máquina insensível e despersonalizada não é recente e já não espanta. O ser humano incorporou ao seu cotidiano o fundamento informacional. Consciente ou inconscientemente transita pelo espaço da informação.

Pode ser que o entendimento desvela-se a partir de um conjunto de eventos cotidianos

\footnotetext{
6 o objetivo de "pensar a informação" não compartilha o interesse de se tentar corrigir supostos "desvios" conceituais, importações de termos inoportunos ou algo parecido.
} 
que estimulam e alimentam a racionalidade. $\mathrm{O}$ conhecimento do senso comum, da experiência sensível e do experimento, de maneira alguma limitam-se às redomas teóricas ou práticas. Há tempos que teoria e prática deixaram de habitar universos diferentes e isolados. O poder do conhecimento está no mais ínfimo fragmento como em seu conjunto. Porém, isso apenas é possível a partir da compreensão de que entre fragmento e conjunto há o espaço relacional, alterando-se constantemente, confundindo e, até mesmo, significando a mesma coisa: a coisa sem sentido.

\section{O contexto e a Filosofia da Informação}

O título de um dos ensaios de Karl Popper é "O mito do contexto" que também dá nome ao livro do qual faz parte (POPPER, 1999). Nele, Popper reflete sobre o contexto que representa consenso. Decididamente refuta essa idéia (POPPER, 1999, p.57), pois, não acredita que haja desenvolvimento de conhecimento racional num ambiente que comporte uniformidade de idéias.

Não acredito na teoria corrente segundo a qual, para tornarem uma discussão fecunda, os opositores têm de ter muita coisa em comum. Pelo contrário, creio que quanto mais diferem os seus backgrounds, mais fecunda é a argumentação. Não há sequer necessidade de uma linguagem comum para se começar: se não tivesse havido uma torre de Babel, teríamos tido de construir uma. A diversidade torna a discussão crítica fecunda (POPPER, 1987, p.40).

E continua, um pouco mais adiante, afirmando que:

Não tenho, pois, qualquer fé na precisão: sou de opinião que a simplicidade e a clareza são valores em si mesmos, mas não de que a precisão ou 'exactidão' seja um valor em si mesma. A clareza e a precisão são aspirações diferentes e, por vezes, até incompatíveis. Não acredito naquilo a que frequentemente se chama uma 'terminologia exacta': não acredito em definições, e não acredito que as definições aumentem a exactidão; e detesto especialmente as terminologias pretensiosas e a pseudo-exactidão que Ihes corresponde (POPPER, 1987, p.41).

As discussões em torno das idéias de Popper já são suficientemente disseminadas e conhecidas (em Ciência da Informação com Miranda (2002) e Robredo (2003), por exemplo), porém, cabe o registro: um sistema onde prevalece a igualdade de pensamentos, só o faz por subordinação e autoritarismo - para controle. Pinker (2004), retomando a crítica à "tabula rasa" (o ser humano nasce sem nenhum tipo de informação - uma folha em branco; o meio é o responsável pela sua formação e atitudes), fornece um conjunto de argumentos sobre a predisposição humana (através de mecanismos cerebrais, por exemplo) à informação, ou seja, a informação da informação. Em paradoxo, Demo (2000) diz que "O problema da informação manipulada, contudo, não deveria nos perturbar em demasia, porque lhe faz parte" (DEMO, 2000, p.40).

Nessa situação, o contexto pode até deixar de ser um mito. Eis aqui um dos preceitos modernos que talvez tenha sido desenvolvido e aprimorado na tentativa de manter uma uniformização ou padronização dos sentidos. A menção, feita por Popper (1999), ao "mito do contexto" pode possuir significado distinto. O que se está tratando aqui não são apenas as características particulares para o desenvolvimento do conhecimento, mas, o condicionamento quase global de um certo tipo de conhecimento que, na realidade, é informação.

Por outro lado, não há como estabelecer marcos conceituais e muito menos históricos precisos. Koyré (1991) esclarece que: 
A história não opera através de saltos bruscos; e as divisões nítidas em períodos e épocas só existem nos manuais escolares. Desde que se comece a examinar as coisas um pouco mais de perto, desaparecem as fronteiras que se acreditava perceber anteriormente; os contornos se desfazem e uma série de gradações insensíveis nos levam de Francis Bacon a seu homônimo do século XIII, e os trabalhos dos historiadores $e$ eruditos do século $X X$ nos fizeram ver, passo a passo, um homem moderno em Roger Bacon e um retardado em seu célebre homônimo; 'recolocaram' Descartes na tradição escolástica e consideraram que o início da filosofia moderna se situa em Santo Tomás. Em geral, o termo 'moderno' tem algum sentido? Somos sempre modernos, em qualquer época, quando pensamos mais ou menos como nossos contemporâneos e de modo um pouco diferente do dos nossos mestres... Nos moderni, já dizia Roger Bacon... (KOYRÉ, 1991, p.15).

Pode ser que este seja um problema de contexto ou de um perspectivismo inflexível e, até mesmo injusto, porém, ressalva-se a importância de marcos temporais às visões panorâmicas. Mesmo porque, esse é um ponto de confusão sobre a pós-modernidade, pois, ela propicia a convivência e possíveis relações de pensamentos, mesmo os mais dogmáticos, desde que se proponham à transformação e à mudança em seus princípios de Domínio e de Racionalidade.

Oportunamente, Koyré (1991) aborda o período moderno em um quase paradoxo com o termo "moderno", o que possibilita modernidades (termo) na pós-modernidade (período). Parece também que a prudência, ao contrário do que se pensa, está em conformidade com o conhecimento na pós-modernidade (SANTOS, 2004). A maturidade pós-moderna explicita-se na passagem dos debates conceituais ao desenvolvimento e aprofundamento de suas teorias. Esse abandono de superfície aponta para uma possível consolidação conceitual provisória que, justificada a ambigüidade como necessária, se distancia dos remanescentes projetos neo-modernos.

Dessa maneira, o comportamento da informação parece inteligível e, ao mesmo tempo, ininteligível. É enigmático o processo informacional visto dessa forma. Como imaginar a informação se auto-construindo, se auto-gerando, se auto-organizando e se auto-destruindo (des-construindo) sem o domínio e o controle humanos? O que se chama de "novos paradigmas", "revoluções paradigmáticas", "revoluções científicas", "ciências novas", "sociedade pós-industrial", "sociedade do conhecimento", "sociedade da informação", "sociedade de consumo", "sociedade pós-moderna", acabaram por tornar-se respostas possíveis às suas próprias indagações.

\section{CONSIDERAÇÕES FINAIS}

O principal objetivo desse texto foi o de mostrar possibilidades de parcerias disciplinares e não o de dissecar essas disciplinas. Concorda-se que talvez a informação não seja objeto exclusivo da Ciência da Informação, porém, alerta-se para o fato de uma idéia como essa poder portar um caráter ambíguo: pode tanto causar estímulos a uma pesquisa consciente e produtiva como pode ser o paradoxal "combustível" à morosidade e ao comodismo.

Como objeto "mutante", a informação em sua pluralidade conceitual está à espera de uma abordagem filosófica que possa contribuir para a revisão e constituição de teorias no campo da Ciência da Informação. O pensamento filosófico, como aqui está sendo abordado e entendido, consiste em um grande desafio que envolve a 
construção de teorias em conformidade com a des-construção de outras teorias.

Ora, nem o conhecimento filosófico nem o científico constituíram-se única e exclusivamente por uma vontade racional e consciente de produção de conhecimento à sociedade. Angústia, inveja, ganância, orgulho, vaidade e raiva podem estar na base de muita ciência e de muita filosofia já desenvolvidas. A Filosofia da Informação não se constitui como método da verdade, mas da dúvida. Postura que contempla uma realidade apropriada pelo ser humano, na qual o conhecimento tenta ser conhecimento e a ciência tenta ser ciência.

\section{R E F E R E N C I A S}

ARAÚJO, E.A. O fenômeno informacional na Ciência da Informação: abordagem teórico-conceitual. In: CASTRO, C.A. (Org.). Ciência da Informação e Biblioteconomia: múltiplos discursos. São Luís: EDUFMA/EDFAMA, 2002.

BRENNAND, E.G.G. Uma nova política de civilização: a sociedade informacional. In: AQUINO, M.A. (Org.). O campo da Ciência da Informação: gênese, conexões e especificidades. João Pessoa: Editora Universitária UFPB, 2002.

BOURDIEU, P. Os usos sociais da ciência: por uma sociologia clínica do campo científico. São Paulo: Unesp, 2004.

BRAGA, G.M. Informação, ciência, política científica: o pensamento de Derek de Solla Price. Ciência da Informação, v.3, n.2, p.155-177, 1974.

DEMO, P. Ambivalências da sociedade da informação. Ciência da Informação, v.29, n.2, p.37-42, 2000.

EUGÊNIO, M.; FRANÇA, Ricardo O.; PEREZ, R.C. Ciência da Informação sob a ótica paradigmática de Thomas Kuhn: elementos de reflexão. Perspectivas em Ciência da Informação, v.1, n.1, p.27-39, 1996.

FERRATER MORA, J. Dicionário de filosofia. 5.ed. Lisboa: Publicações Dom Quixote, 1982.
Pensar a informação para a geração de conhecimento sobre a própria informação. Pensar as suas relações. Pensar a informação em seus múltiplos e paradoxais modos de apresentação. Pensar a informação que não se apresenta, que parece estar na obscuridade, que parece estar perdida, que parece que não é informação. Pensar o que é, o que não é e o que pode ou não ser informação. Pensar o por que é e o por que não é informação, o por que pode ou não pode ser informação e assim por diante. Enfim, pensar a informação, não importando, paradoxalmente, em que contexto e em qual situação ela se encontre.

FLORIDI, L. On defining library and information science as applied philosophy of information. Social Epistemology, v.16, n.1, p.37-49, 2002a. Available from: <http://www.wolfson.ox.ac.uk/ floridi/>. Acess: 14 May 2004.

FLORIDI, L. Open problems in the philosophy of information. Metaphilosophy, v.35, n.3, Apr. 2004. Available from: <http://www.wolfson.ox.ac.uk/ floridi>. Acess: 25 Jun. 2004.

FLORIDI, L. What is philosophy of information? Metaphilosophy, v.33, n.1/2, p.123-145, 2002b. Available from: <http://www.wolfson.ox.ac.uk/ floridi>. Acess: 14 May 2004.

FOSKETT, D.J. Informática. In: GOMES, H.E. (Org.). Ciência da Informação ou Informática? Rio de Janeiro: Calunga, 1980.

HARRIS, K. Cidadania e localidade na sociedade em rede: criando riqueza na diversidade. In: AQUINO, M.A. (Org.). O campo da Ciência da Informação: gênese, conexões e especificidades. João Pessoa: Editora Universitária UFPB, 2002.

ILHARCO, F. Filosofia da informação. Lisboa: Universidade Católica Portuguesa, 2003.

JAPIASSU, H. As máscaras da ciência. Ciência da Informação, v.5, n.1, p.13-15, 1977.

KOYRÉ, A. Estudos de história do pensamento científico. 2.ed. Rio de Janeiro: Forense Universitária, 1991. 
KUHN, T.S. A estrutura das revoluções científicas. 6.ed. São Paulo: Perspectiva, 2001.

LE COADIC, Y.F. A Ciência da Informação. Brasília: Briquet de Lemos/Livros, 1996.

LEVY, P. A inteligência coletiva: por uma antropologia do ciberespaço. 2.ed. São Paulo: Loyola, 1999.

LEVY, P. As tecnologias da inteligência: o futuro do pensamento na era da informática. Rio de Janeiro: Editora 34, 2000.

McGARRY, K. O contexto dinâmico da informação. Brasília: Briquet de Lemos/ Livros, 1999.

MIRANDA, A. A Ciência da Informação e a teoria do conhecimento objetivo: um relacionamento necessário. In: AQUINO, M.A. (Org.). O campo da Ciência da Informação: gênese, conexões e especificidades. João Pessoa: Editora Universitária UFPB, 2002.

MOSTAFA, S.P. Epistemologia da Biblioteconomia. 1985. Tese (Doutorado) - Faculdade de Biblioteconomia, Pontifícia Universidade Católica de São Paulo, São Paulo, 1985.

NEHMY, R.M.Q. et al. A Ciência da Informação como disciplina científica. Perspectivas em Ciência da Informação, v.1, n.1, p.9-25, 1996.

PAIVA, C.C. O campo híbrido da informação e da comunicação. In: AQUINO, M.A. (Org.). O campo da Ciência da Informação: gênese, conexões e especificidades. João Pessoa: Editora Universitária/UFPB, 2002.

PINHEIRO, L.V.R. (Org.). Ciência da Informação, Ciências Sociais e interdisciplinaridade. Rio de Janeiro: IBICT, 1999.

PINKER, S. Tábula rasa: a negação contemporânea da natureza humana. São Paulo: Companhia das Letras, 2004.

POPPER, K.R. O mito do contexto: em defesa da ciência e da racionalidade. Lisboa: Edições 70, 1999.

POPPER, K.R. O realismo e o objectivo da ciência: pós-escrito à Lógica da Descoberta Científica.
Lisboa, Portugal: Publicações Dom Quixote, 1987. v.1.

ROBREDO, J. Da Ciência da Informação revisitada aos sistemas humanos de informação. Brasília: Thesaurus, 2003.

RODRIGUES, A.D. Comunicação e cultura: a experiência cultural na era da informação. 2.ed. Lisboa, Portugal: Editorial Presença, 1999.

SAN SEGUNDO MANUEL, R. Nueva concepción del conocimiento. In: RODRIGUES, G.M.; LOPES, I.L. (Org.). Organização e representação do conhecimento na perspectiva da Ciência da Informação. Brasília: Thesaurus, 2003. (Estudos Avançados em Ciência da Informação, v.2).

SANTOS, B.S. (Org.). Conhecimento prudente para uma vida decente: 'um discurso sobre as ciências' revisitado. São Paulo: Cortez, 2004.

SANTOS, L.G. Politizar as novas tecnologias: o impacto sócio-técnico da informação digital e genética. São Paulo: Editora 34, 2003.

SARACEVIC, T. Tecnologia da informação, sistemas de informação e informação como utilidade pública. Ciência da Informação, v.3, n.1, p.57-67, 1974.

SILVA, A.M. Conhecimento/informação: sinonímia e/ou diferenciação? In: RODRIGUES, G.M.; LOPES, I.L. (Org.). Organização e representação do conhecimento na perspectiva da Ciência da Informação. Brasília: Thesaurus, 2003. (Estudos Avançados em Ciência da Informação, v.2).

SILVA, J. Informação e auto-organização. In: DEBRUN, M.; PESSOA JR, O.; QUILICI GONZALES, M.E. (Org.). Auto-organização: estudos interdisciplinares em filosofia, ciências naturais e humanas, e artes. Campinas: Unicamp, 1996. (Coleção CLE. v.18).

WERTHEIN, J. A sociedade da informação e seus desafios. Ciência da Informação, v.29, n.2, p.71-77, 2000.

WILDEN, A. Informação. In: ENCICLOPEDIA Einaudi. Comunicação, cognição. Lisboa: Imprensa Nacional, 2000. v.34. 